\title{
Serum concentrations of PIIINP aminopeptide in dogs with liver fibrosis
}

\author{
K. Glińska-Suchocka1 ${ }^{1}$, A. Orłowska², M. Jankowski' ${ }^{1}$ K. Kubiak ${ }^{1}$ J. Spużak ${ }^{1}$ \\ ${ }^{1}$ Department of Internal Diseases with Clinic of Horses, Dogs and Cats, Faculty of Veterinary Medicine, \\ Wroclaw University of Environmental and Life Sciences, pl. Grunwaldzki 47, 50-366 Wrocław, Poland \\ ${ }^{2}$ Department of Biochemistry, Pharmacology and Toxicology, Faculty of Veterinary Medicine, \\ Wroclaw University of Environmental and Life Sciences, Norwida 31, 50-375 Wrocław, Poland
}

\begin{abstract}
The aim of the study was to evaluate the serum concentration of the type III procollagen aminopeptide in dogs, and to assess its utility in the diagnosis of liver fibrosis. The study was carried out on 20 dogs of different breeds and of both genders, between 7 and 15 years old. Based on the results of the histopathological examination and the evaluation of the degree of liver fibrosis, the dogs were divided into five groups. The mean serum PIIINP concentration in the group of dogs with stage 1 and 2 liver fibrosis (groups 2 and 3) was five-fold higher than in healthy dogs (group 1). In turn, the mean PIIINP concentration in the group of dogs with stage 3 (group 4) and stage 4 (group 5) fibrosis was 10-fold higher than that of the control group (group 1). Based on the results, we found that the serum PIIINP concentration correlated with the degree of liver fibrosis, assessed based on a histopathological examination. Therefore, PIIINP serum concentration tests may be a promising non-invasive diagnostic technique that could be used in veterinary hepatology to assess the degree of liver fibrosis.
\end{abstract}

Key words: dog, serum PIIINP, liver fibrosis

\section{Introduction}

Currently, liver diseases in veterinary medicine pose a serious diagnostic challenge for the clinician. The most common causes of liver damage are viral and bacterial infections as well as toxic substances. The liver suffers from damage, remodelling and fibrosis in response to a toxic and infectious agent.

The term ,liver fibrosis” refers to a constant, excessive deposition of components of the extracellular matrix (ECM) and a change in the proportion of its components, leading to tissue hypertrophy, hardening and scarring (Kruś 2007, Guarino et al. 2009, Pinzani and Macias-Barragan 2010).

In most cases, a core needle biopsy is performed to correctly assess the degree of liver inflammation and fibrosis. Currently, in human medicine, there are numerous studies under way aimed at developing a panel of non-invasive markers, which may be used to assess the degree of liver fibrosis. These markers are required to have high liver specificity, a high sensitivity to fibrinolysis and synthesis of components of the ECM, and are expected to give repeatable results (Gutkowski et al. 2007). Based on those studies, we attempted to

Correspondence to: K. Glińska-Suchocka, e-mail: kamila.glinska@up.wroc.pl 
evaluate some non-invasive markers of liver fibrosis in dogs. One such marker is the type III procollagen aminopeptide (PIIINP), which indicates an accumulation of the extracellular matrix. To date, the usefulness of PIIINP in the diagnosis of liver fibrosis has not been studied in veterinary medicine. In 2013, Heikkila et al. assessed the utility of analyzing serum PIIINP in the diagnosis of lung and bronchial disease. Hazzeli et al. (2014) evaluated serum PIIINP concentrations in myxomatous mitral valve disease.

The aim of our study was to evaluate the serum concentration of the type III procollagen aminopeptide in dogs and to assess its utility in the diagnostics of liver fibrosis.

\section{Materials and Methods}

The study was carried out on 20 dogs of different breeds (ten mixed-breed dogs, two Labrador retrievers, three cocker spaniels, three German shepherds, one miniature poodle and one Yorkshire terrier) and of both genders ( 15 males, 5 females) between 7 and 15 years old. All dogs were suspected of having a chronic liver parenchyma damage and were referred to the Clinic of the Department of Internal Diseases with Clinic of Horses, Dogs and Cats for a liver biopsy. Systemic diseases and diseases of other organs were excluded in each animal based on a clinical examination, laboratory test results and an abdominal ultrasound examination. Blood samples were drawn from each dog, and a basic blood biochemistry (AST, ALT, ALP, GGT, total bilirubin) was carried out. Additionally, serum samples were obtained by centrifuging EDTA anticoagulated blood and stored at $-20^{\circ} \mathrm{C}$. The Serum PIIINP level was determined using a Canine Procollagen Type III N-Terminal Propeptide ELISA Kit (MyBioSource, San Diego, USA).

A core needle biopsy of the liver under ultrasound guidance was carried out in all animals using a Tru - Cut needle $(20 \mathrm{~cm}$ long, $16 \mathrm{G})$. In all the animals, numerous hepatic lesions were visible by ultrasound. Consequently, a left-lobe and right-lobe biopsy was obtained from each dog. The specimens were fixed in a $10 \%$ buffered formalin solution. They were then transferred to the histopathology laboratory and underwent an assessment of the degree of liver fibrosis.

A 5 point scale approved by the Hepatology Group of the Polish Society of Gastroenterology was used to assess hepatic fibrosis:

Stage 0 (F0) - normal - no fibrosis, single collagen fibres in portal spaces

Stage 1 (F1) - fibrosis within portal spaces with an extension of the portal tracts
Stage 2 (F2) - peri-portal fibrosis and possibly single bridging fibrosis while maintaining lobular structure,

Stage 3 (F3) - the presence of multiple fibre spans, a destruction of the lobular architecture, no regeneration reaction.

Stage 4 (F4) - disseminated fibrosis or cirrhosis (Goodman 2007).

Using the above classification, we were able to assess the concentration of the type III procollagen aminopeptide depending on the degree of changes in the liver tissue.

The dogs were divided into five groups based on the degree of liver fibrosis:

- group 1, comprising 5 dogs that did not have liver fibrosis $(\mathrm{F} 0)$

- group 2, comprising 3 dogs that had first degree liver fibrosis (F1)

- group 3, comprising 4 dogs that had second degree liver fibrosis (F2)

- group 4, comprising 3 dogs that had third degree liver fibrosis (F3)

- group 5, comprising 5 dogs that had fourth degree liver fibrosis (F4).

Statistical analyses were performed using version 10 of STATISTICA (StatSoft Inc., Poland). Data are expressed as median values. The correlation between serum PIIINP levels and the liver fibrosis were determined with the Students-t test. A p-value of $\leq 0.05$ was considered statistically significant.

\section{Results}

The mean PIIINP serum concentration was 634.25 $\pm 618.41 \mathrm{pg} / \mathrm{ml}$ in group $1,3077.91 \pm 894.046 \mathrm{pg} / \mathrm{ml}$ in group 2, $3030.93 \pm 827.11 \mathrm{pg} / \mathrm{ml}$ in group 3, 5685.83 $\pm 1630.33 \mathrm{pg} / \mathrm{ml}$ in group 4 and $6574.5 \pm 2983.46 \mathrm{pg} / \mathrm{ml}$ in group 5. The results of the chosen biochemical parameters, the serum PIIINP concentrations and the degree of liver fibrosis determined by histopathology of the liver biopsy specimens for each animal and group are shown in Table 1.

Statistically significant differences in the concentrations of PIIINP were found between group 1 and group $2(p=0.0035), 3(p=0.012127), 4 \quad(p=0.0027)$ and $5(\mathrm{p}=0.011817)$. The PIIINP concentration was higher in group 5 than in all the remaining groups. Statistically significant differences in the concentration of PIIINP were also found between group 3 and $4(\mathrm{p}=0.0352)$.

A graphic display of the PIIINP serum concentrations in each study group is presented in Fig. 1. 
Table 1. Results of chosen biochemical parameters, stage of liver fibrosis and PIIINP serum concentrations in each animal and study group.

\begin{tabular}{|c|c|c|c|c|c|c|c|c|}
\hline $\begin{array}{l}\text { Study } \\
\text { group }\end{array}$ & Animal & $\begin{array}{l}\text { AST } \\
{[\mathrm{U} / 1]}\end{array}$ & $\begin{array}{l}\text { ALT } \\
{[\mathrm{U} / 1]}\end{array}$ & $\begin{array}{l}\text { ALP } \\
{[\mathrm{U} / 1]}\end{array}$ & $\begin{array}{l}\text { GGT } \\
{[\mathrm{U} / 1]}\end{array}$ & $\begin{array}{c}\text { Total } \\
\text { bilirubin } \\
{[\mathrm{mmol} / \mathrm{l}]}\end{array}$ & $\begin{array}{l}\text { Stage of } \\
\text { Fibrosis }\end{array}$ & $\begin{array}{l}\text { PIIINP } \\
{[\mathrm{pg} / \mathrm{ml}]}\end{array}$ \\
\hline \multirow{5}{*}{1} & 1 & 78 & 54 & 170 & 5 & 1.8 & 0 & 322.5 \\
\hline & 2 & 32 & 77 & 170 & 1 & 1.8 & 0 & 311.25 \\
\hline & 3 & 52 & 24 & 41 & 4 & 1.8 & 0 & 173.75 \\
\hline & 4 & 31 & 53 & 86 & 2 & 2.6 & 0 & 1690 \\
\hline & 5 & 56 & 138 & 287 & 12 & 2 & 0 & 673.75 \\
\hline \multirow{3}{*}{2} & 1 & 81 & 632 & 61 & 13 & 3 & 1 & 3787.5 \\
\hline & 2 & 43 & 213 & 56 & 1 & 1.8 & 1 & 2073.75 \\
\hline & 3 & 117 & 205 & 160 & 18 & 1 & 1 & 3372.5 \\
\hline \multirow{4}{*}{3} & 1 & 214 & 412 & 214 & 10 & 1 & 2 & 3306.25 \\
\hline & 2 & 214 & 412 & 214 & 10 & 1 & 2 & 1798.75 \\
\hline & 3 & 43 & 34 & 43 & 1 & 2.6 & 2 & 3493.75 \\
\hline & 4 & 64 & 30 & 74 & 13 & 2 & 2 & 3525 \\
\hline \multirow{3}{*}{4} & 1 & 160 & 587 & 382 & 13 & 17 & 3 & 4925 \\
\hline & 2 & 47 & 117 & 468 & 2 & 8.9 & 3 & 7557.5 \\
\hline & 3 & 198 & 277 & 411 & 27 & 5.4 & 3 & 4575 \\
\hline \multirow{5}{*}{5} & 1 & 311 & 1187 & 442 & 29 & 56 & 4 & 9070 \\
\hline & 2 & 234 & 411 & 242 & 2 & 23 & 4 & 5047.5 \\
\hline & 3 & 233 & 1314 & 452 & 16 & 32 & 4 & 3095 \\
\hline & 4 & 320 & 715 & 438 & 20 & 24 & 4 & 5402.5 \\
\hline & 5 & 234 & 411 & 242 & 2 & 76 & 4 & 10257.5 \\
\hline
\end{tabular}

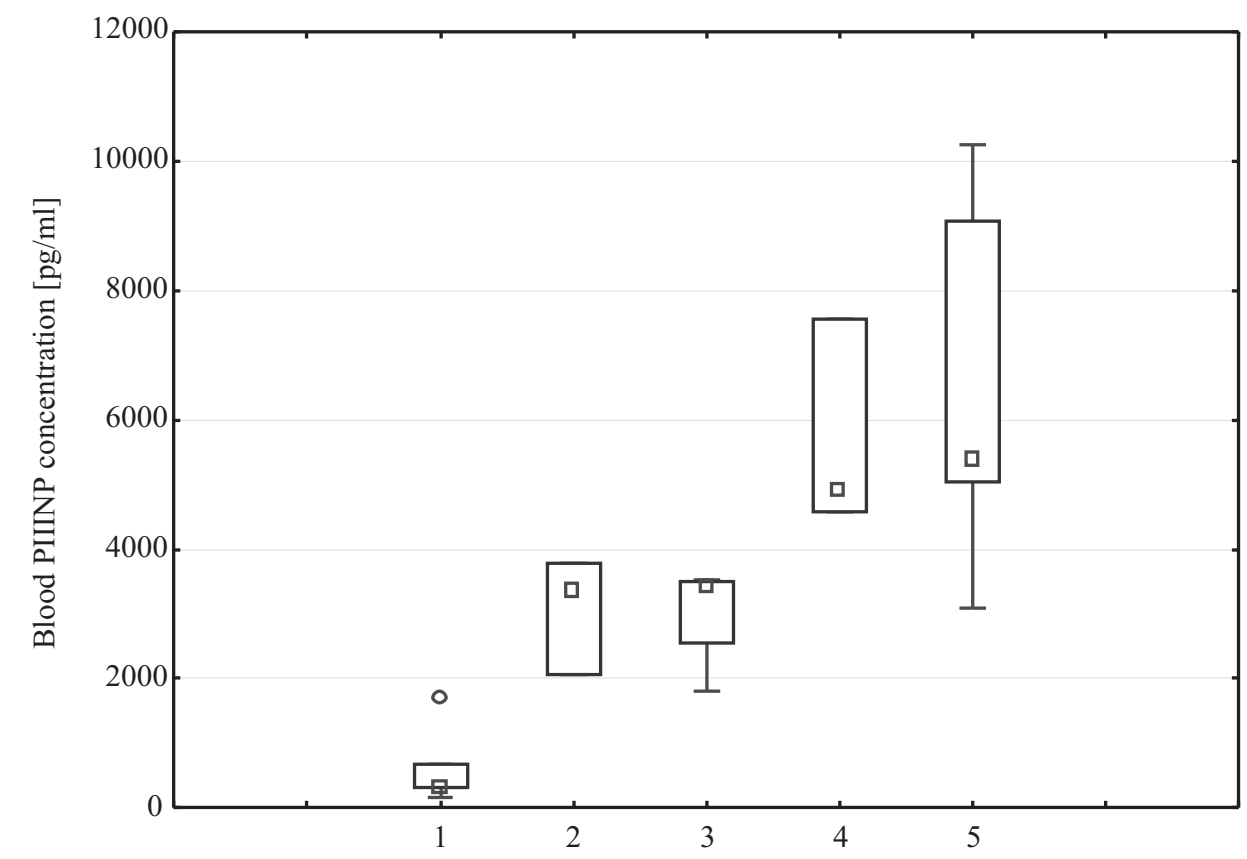

Fig. 1. Box plots of serum PIIINP concentrations in each study group.

\section{Discussion}

Type III procollagen aminopeptide (PIIINP) is a marker than enables an assessment of the function of fibroblasts and type III collagen. During the synthesis of type III collagen, the amino-terminal peptide is released from the collagen molecule and enters circulation. The amount of released peptide is proportional to the amount of the collagen produced (Prockop et al. 1979). In human medicine, numerous studies have been performed to assess the utility of PIIINP in the diagnostics of fibrosis. They revealed 
that this parameter may be useful in the diagnosis of idiopathic pulmonary fibrosis (Norris et al. 2005), obstructive pulmonary disease (Harju et al. 2010), sarcoidosis, (Lammi et al. 1997) and the respiratory distress syndrome (Meduri et al. 1998). In humans, PIIINP has also been found to be associated with the myocardial fraction of type III collagen and may be used as a marker of myocardial fibrosis (Izawa at al. 2005, Klappacher et al. 2005). Apart from its wide use in pulmonology and cardiology, PIIINP has been found to correlate well with the results obtained from microscopic examinations of liver biopsy specimens in patients with alcoholic liver disease, viral hepatitis and primary biliary cirrhosis. Therefore, it is a sensitive marker of liver fibrosis (Gutkowski et al. 2007). In recent years, a commercial enhanced liver fibrosis (ELF) test that non-invasively measures the degree of liver fibrosis has been introduced in human medicine. It assesses three main markers of liver fibrosis - hyaluronic acid (HA), type III procollagen aminopeptide (PIIINP) and the inhibitor of the precursor of metalloproteinase-1 (TIMP1) (Rosenberg et al. 2004, Parkes et al. 2010, Pinzani 2010).

To date, two studies assessing this marker in veterinary medicine have been performed. One evaluated the utility of PIIINP concentrations in the serum and bronchoalveolar lavage fluid (BALF) by radioimmunoassay in healthy dogs and in dogs with idiopathic pulmonary fibrosis (IPF), chronic bronchitis (CB) and eosinophilic bronchopneumopathy (EBP) (Heikkilä at al. 2013). The other study determined the associations between type III N-terminal procollagen, fibrosis and echocardiographic indices in dogs that died due to myxomatous mitral valve disease (Hazzell at al. 2014). The study conducted by Heikkila (Heikkilä at al. 2013) revealed that serum PIIINP values did not differ between groups, indicating that serum PIIINP is not useful in evaluating respiratory diseases in dogs. However, BALF PIIINP concentrations were significantly higher in dogs with EBP than in dogs with CB or in healthy dogs. In turn, the study by Hazzell (Hazzell et al. 2014) showed that serum PIIINP concentrations increased with the fibrosis score, although those relationships were not strong enough to be clinically useful. In veterinary medicine, there are no available studies assessing PIIINP role in the diagnosis of canine liver fibrosis. In view of the usefulness of this parameter in human medicine, we attempted to assess the suitability of PIIINP in the diagnosis of liver fibrosis in dogs with varying degrees of liver damage.

In 1986, Torres-Salinas (Torres-Salinas et al. 1986) conducted one of the first studies on the utility of analysing serum PIIINP levels to diagnose liver fibrosis. He measured the PIIINP concentrations in two groups of patients with alcoholic liver disease. Based on the results, he concluded that patients who developed severe liver fibrosis had significantly higher concentrations of PIIINP $(1208 \pm 154 \mathrm{cpm} / \mathrm{mg})$ than patients who did not develop liver fibrosis $(734 \pm 138$ $\mathrm{cpm} / \mathrm{mg}$ ) (Torres-Salinas et al. 1986). His findings were confirmed by other scientists in various research centers (Bentsen et al 1978, Nouchi et al. 1987, Trinchet et al. 1992, Oberti et al. 1997, Tran et al. 2000, Stickel et al. 2001). However, we failed to find a correlation between the concentrations of PIIINP and the degree of liver damage in the available literature. Our study showed that dogs with severe liver fibrosis had significantly increased concentrations of PIIINP. The mean PIIINP concentrations in group 2 and 3 were almost five-fold higher than in healthy dogs (group 1). The mean PIIINP concentrations in group 4 and 5 were 10 -fold greater than those in the control animals. In addition, based on the results, we found no statistically significant differences in the concentrations of serum PIIINP between groups 2 and 3 (dogs with have stage 1 and 2 liver fibrosis) and groups 4 and 5 (dogs with stage 3 and 4 liver fibrosis).

Based on the results, we found that the serum PIIINP concentrations correlated with the degree of liver fibrosis assessed histopathologically. Therefore, the determination of serum concentrations of PIIINP seems as a promising non-invasive diagnostic technique that can be used in veterinary hepatology to assess the degree of liver fibrosis. However, further research is needed on a larger study group including animals of different ages.

\section{Acknowledgements}

Article publication supported by Wrocław Centre of Biotechnology, programme the Leading Notional Research Centre (KNOW) for years 2014-2018.

\section{References}

Bentsen KD, Horn T, Risteli J, Risteli L, Engstrom-Laurent A, Hørslev-Petersen K, Lorenzen I (1987) Serum aminoterminal type III procollagen peptide and the $7 \mathrm{~S}$ domain of type IV collagen in patients with alcohol abuse. Relation to ultrastructural fibrosis in the acinar zone 3 and to serum hyaluronan. Liver 7: 339-346.

Goodman ZD (2007) Grading and staging systems for inflammation and fibrosis in chronic liver diseases. J Hepatol 47: 598-607.

Guarino M, Tosoni A, Nebuloni M (2009) Direct contribution of epithelium to organ fibrosis: epithelial-mesenchylam transition. Hum Pathol 40: 1365-1376.

Gutkowski K, Kamińska E, Pluta A (2007) The role of non-invasive diagnostics in assessment of hepatic fibrosis progression. Gastroenterol Pol 14: 363-367. 
Harju T, Kinnula VL, Paakko, P, Salmenkivi K, Risteli J, Kaarteenaho R (2010) Variability in the precursor proteins of collagen I and III in different stages of COPD. Respir Res 11: 165.

Heikkilä HP, Krafft E, Jespers P, McEntee K, Rajamäki MM, Clercx C (2013) Procollagen type III amino terminal propeptide concentrations in dogs with idiopathic pulmonary fibrosis compared with chronic bronchitis and eosinophilic bronchopneumopathy Vet J 196: 52-56.

Hezzell MJ, Falk T, Olsen LH, Boswood A, Elliott J (2014) Associations between N-terminal procollagen type III, fibrosis and echocardiographic indices in dogs that died due to myxomatous mitral valve disease $\mathrm{J}$ Vet Cardiol 16: 257-264,

Izawa $\mathrm{H}$, Murohara $\mathrm{T}$, Nagata $\mathrm{K}$, Isobe $\mathrm{S}$, Asano $\mathrm{H}$, Amano $\mathrm{T}$, Ichihara S, Kato T, Ohshima S, Murase Y, Iino S, Obata K, Noda A, Okumura K, Yokota M (2005) Mineralocorticoid receptor antagonism ameliorates left ventricular diastolic dysfunction and myocardial fibrosis in mildly symptomatic patients with idiopathic dilated cardiomyopathy: a pilot study. Circulation 112: 2940-2945.

Klappacher G, Franzen P, Haab D, Mehrabi M, Binder M, Plesch K, Pacher R, Grimm M, Pribill I, Eichler HG, Glogar HD (1995) Measuring extracellular matrix turnover in the serum of patients with idiopathic or ischemic dilated cardiomyopathy and impact on diagnosis and prognosis. Am J Cardiol 158: 1432-1441.

Kruś S, Skrzypek-Fakhoury E (2007) Patomorfologia kliniczna. 3th ed., PZWL, Warszawa.

Lammi L, Kinnula V, Lähde S, Risteli J, Pääkkö P, Lakari E, Ryhänen L (1997) Propeptide levels of type III and type I procollagen in the serum and bronchoalveolar lavage fluid of patients with pulmonary sarcoidosis. Eur Respir J 10: 2725-2730.

Meduri GU, Tolley EA, Chinn A, Stenzt F, Postlethwaite A (1998). Procollagen types I and III aminoterminal propeptide levels during acute respiratory distress syndrome and in response to methylprednisolone treatment. Am J Respir Crit Care Med 158: 1432-1441.

Norris, AJ, Naydan DK, Wilson DW (2005) Interstitial lung disease in West Highland White Terriers. Vet Pathol 42: 35-41.

Nouchi T, Worner TM, Sato S, Lieber CS. (1987) Serum procollagen type III N-terminal peptides and laminin P1 peptide in alcoholic liver disease. Alcohol Clin Exp Res 11: 287-291.
Oberti F, Valsesia E, Pilette C, Rousselet MC, Bedossa P, Aubé C, Gallois Y, Rifflet H, Maïga MY, Penneau-Fontbonne D, Calms P (1997) Noninvasive diagnosis of hepatic fibrosis or cirrhosis. Gastroenterology 113: $1609-1616$.

Parkes J, Roderick P, Harris S, Day C, Mutimer D, Collier J, Lombard M, Alexander G, Ramage J, Dusheiko G, Wheatley M, Gough C, Burt A, Rosenberg W. (2010) Enhanced Liver Fibrosis Test Can Predict Clinical Outcome in Patients with Chronic Liver Disease' Gut 59: $1245-1251$

Pinzani M (2010) The ELF panel: a new crystal ball in hepatology? Gut 59: 1165-1167.

Pinzani M, Macias-Barragan J (2010) Update on the pathophysiology of liver fibrosis. Expert Rev Gastroenterol Hepatol 4: 459-472.

Prockop DJ, Kivirikko KI, Tuderman L, Guzman NA (1979) The biosynthesis of collagen and its disorders, N Engl J Med 301: 13-23.

Rosenberg WM, Voelker M, Thiel R, Becka M, Burt A, Schuppan D, Hubscher S, Roskams T, Pinzani M, Arthur MJ (2004) Serum Markers Detect the Presence of Liver Fibrosis: A Cohort Study Gastroenterology 127: 1704-1713.

Stickel F, Urbaschek R, Schuppan D, Poeschl G, Oesterling C, Conradt C, McCuskey RS, Simanowski UA, Seitz HK (2001) Serum collagen type VI and XIV and hyaluronic acid as early indicators for altered connective tissue turnover in alcoholic liver disease. Dig Dis Sci 46: 2025-2032.

Torres-Salinas M, Parés A, Caballería J, Jiménez W, Heredia D, Bruguera M, Rodés J (1986) Serum procollagen Type III peptide as a marker of hepatic fibrogenesis in alcoholic hepatitis. Gastroenterology 90: 1241-1246.

Tran A, Benzaken S, Saint-Paul MC, Guzman-Granier E, Hastier P, Pradier C, Barjoan EM, Demuth N, Longo F, Rampal P (2000) Chondrex (YKL-40), a potential new serum fibrosis marker in patients with alcoholic liver disease. Eur J Gastroenterol Hepatol 12: 989-993.

Trinchet JC, Hartmann DJ, Pateron D, Munz-Gotheil C, Callard P, Ville G, Beaugrand M (1992) Serum Type I collagen and N-terminal peptide of Type III procollagen in patients with alcoholic liver disease: relationship to liver histology. Alcohol Clin Exp Res 16: 342-346. 